\title{
Three worlds of health technology assessment: explaining patterns of diffusion of HTA agencies in Europe - CORRIGENDUM
}

OLGA LÖBLOVÁ

doi:10.1017/S1744133115000444, published online by Cambridge University Press 16 December 2015.

There were errors made in the following text references. The correct text references are produced below. The publisher apologies for these errors.

Page 2 , Line 5

...EUnetHTA (Böhm and Landwehr, 2014; Greer and Löblová, 2016), a network of HTA bodies...

Page 13, Line 2

...HTA has not been high enough on the priority list for the European Commission (Greer and Löblová, 2016) - certainly not enough...

Page 16, Line 2

... of HTA agencies' fate in Poland and the Czech Republic (Löblová, unpublished manuscript) suggest that epistemic...

\section{Reference}

Löblová, O. (2015), 'Three worlds of health technology assessment: explaining patterns of diffusion of HTA agencies in Europe', doi:10.1017/S1744133115000444. 